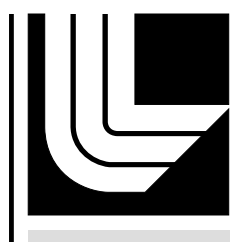

LAWRENCE LIVERM ORE N A TIO NAL LABORATORY

Antiscalent Field Testing for the LBNE Facility

W. D. Daily

October 13, 2011 
This document was prepared as an account of work sponsored by an agency of the United States government. Neither the United States government nor Lawrence Livermore National Security, LLC, nor any of their employees makes any warranty, expressed or implied, or assumes any legal liability or responsibility for the accuracy, completeness, or usefulness of any information, apparatus, product, or process disclosed, or represents that its use would not infringe privately owned rights. Reference herein to any specific commercial product, process, or service by trade name, trademark, manufacturer, or otherwise does not necessarily constitute or imply its endorsement, recommendation, or favoring by the United States government or Lawrence Livermore National Security, LLC. The views and opinions of authors expressed herein do not necessarily state or reflect those of the United States government or Lawrence Livermore National Security, LLC, and shall not be used for advertising or product endorsement purposes.

This work performed under the auspices of the U.S. Department of Energy by Lawrence Livermore National Laboratory under Contract DE-AC52-07NA27344. 


\title{
Antiscalant Field Testing for the LBNE Facility
}

\author{
William Daily, Sally Bahowick, LLNL
}

\begin{abstract}
Summary
This paper was intended as an overview of options and considerations related to the field testing of an antiscalant injection system to be used on a cooling water system where minimal equipment, costs, energy, footprint, and maintenance are desired. It is anticipated that engineering oversight and judgment will be utilized to determine the applicability of each parameter and process suggested herein and modify the plan as necessary prior to implementation. Comparisons between options are given to weigh the benefits of each approach. Suggestions for equipment, materials, automation, monitoring and analytical are provided based on experience and industrial standards and may not be applicable for specific field applications.
\end{abstract}

\section{Introduction}

A recent design requirement for supplied cooling water to the heat exchangers and associated pumps and piping, used for the Long Baseline Neutrino Experiment (LBNE) in the Homestake Mine, South Dakota, is to add a system to control hard water scaling. This would enable the various systems to operate with increased efficiency by limiting the buildup of calcium carbonates (scale) on wetted surfaces which tend to bind pump impellers, increase pipeline friction, decrease flow crosssectional areas, and decrease heat transfer coefficients. This is especially pertinent as it is anticipated that groundwater, typically high in dissolved solids, will be used as the water source. Based on literature searches, previous experience and manufacturer recommendations, it was decided to investigate the applicability of antisclalent additives known for its use in industrial applications. The purpose of this paper is to outline the field-testing and verification of the effectiveness of antiscalent, specifically Belsperse 161, for use in cooling water at the DUSEL facility.

\section{Equipment and Processes}

The system requiring scale control will supply groundwater to a heat exchanger, at about 5,000 feet underground, as part of the LBNE water treatment system. The groundwater conveyance components consists of a subterranean wellhead, booster pump, filtration, antiscalent injection system, about 2500 feet of pipeline, heat exchanger, and additional pipeline with one or more additional booster pumps (Figure 1). The water is Then pumped to the surface where it is processed through the a treatment system consisting of filtration for iron removal and bioremediation for ammonia assimilation. 


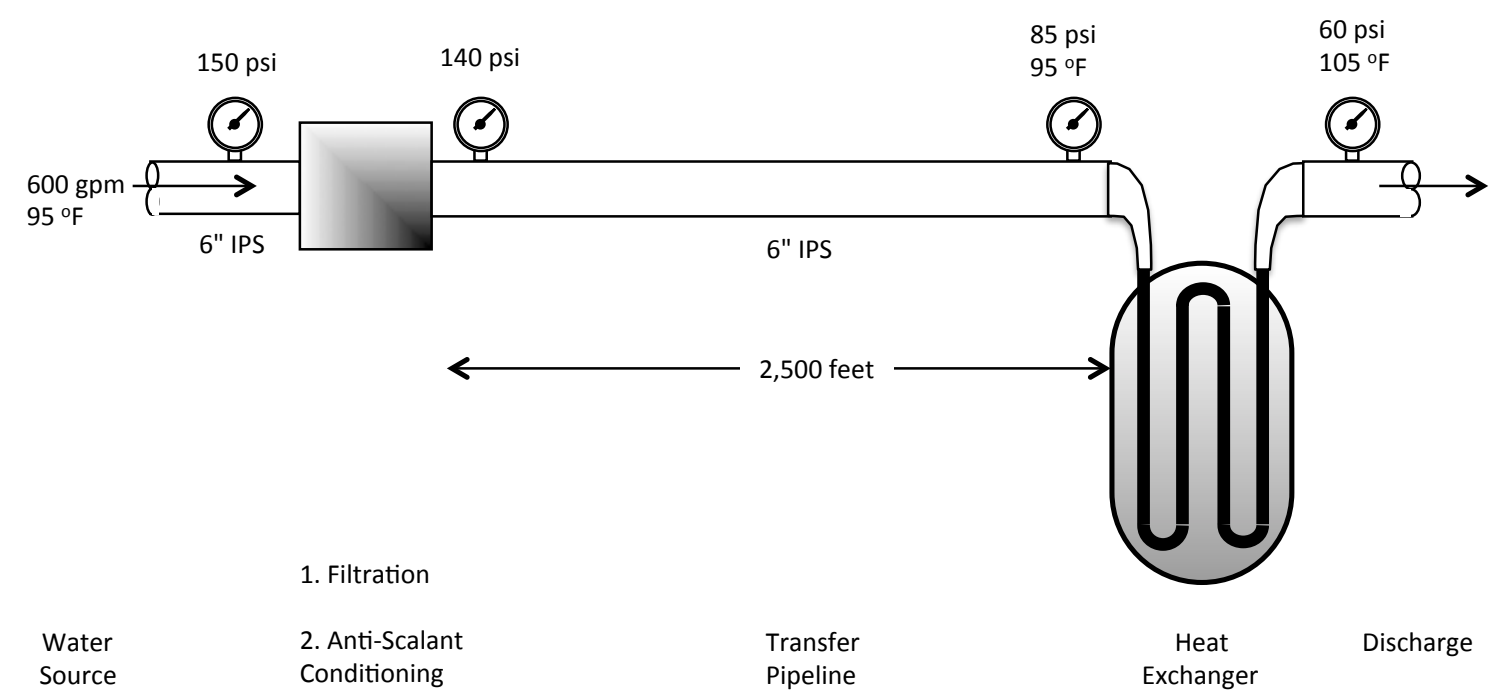

Figure 1 Basic cooling system components

Systematic processes that could negatively affect the performance of Belsperse 161 include the rise in temperature within the heat exchanger, and the potential addition of air into the system. The ground water is typically hard water with high concentrations of iron and ammonia that require treatment prior to discharge to surface sources ${ }^{1}$ (attached). The water characteristics that typically affect the efficiency of de-scaling include $\mathrm{pH}$, dissolved ion concentrations, TSS concentrations, water temperature and competing chemistries in the water. Another process that could affect the scaling potential is a dramatic change in pressure as may be expected from the pumping of water 5,000 feet to the ground surface. Depending on the pumping mechanics, pressure differences can allow degassing which could change $\mathrm{pH}$ and thus alter the solubility of dissolved minerals.

Due to the uncertain effect of these parameters on scale precipitation and buildup, it is recommended that a field test be performed that would quantify the effectiveness of descaling with Belsperse 161 for various dosing rates under the anticipated conditions.

With regards to the bioreactor, it's not anticipated that the addition of antiscalant would have a negative effect on its ability to maintain a microbial colony. It has been shown that antiscalants containing phosphorous may accelerate the growth of microbes because they themselves are a nutrient source ${ }^{2}$. Belsperse 161 is derived from the composition of 2-Propenoic Acid, Polymer with Sodium Phosphinate and water. From the MSDS for Belsperse 161, "thermal decomposition and burning may produce carbon monoxide, carbon dioxide and phosphorous oxides". It's not classified as hazardous to health or the environment.

\footnotetext{
1 Facility Cooling Water Scaling Issues, Research Memo for Sally Bahowick, William Daily, LLNL, 2011

2 Reverse Osmosis: Design, Processes,and Applications for Engineers, Jane Kucera
} 
In a paper written at $\mathrm{LLNL}^{3}$, documenting the testing of Belsperses 161, it states that "Phosphate in treated ground water discharged to the retention basin can stimulate algae blooms by providing algae with a nutrient source...A greater than a 10 -fold decrease in o-phosphate occurred when JP-7 (an alternative antiscalant) was replaced with Belsperse 161 at an injection rate of $1.5 \mathrm{mg} / \mathrm{L}$." This would infer that although Belsperse 161 has lower concentrations of phosphate that some antiscalants, it's still enough to stimulate algae growth. The effect of this on the bioreactor is beyond the scope of this paper.

The final design of an antiscalant system may consist of a reservoir to hold the chemical, a dosing pump, a calibration column, flow indicators and a mixing apparatus (Figure 2). The test setup would likely include most of these components.

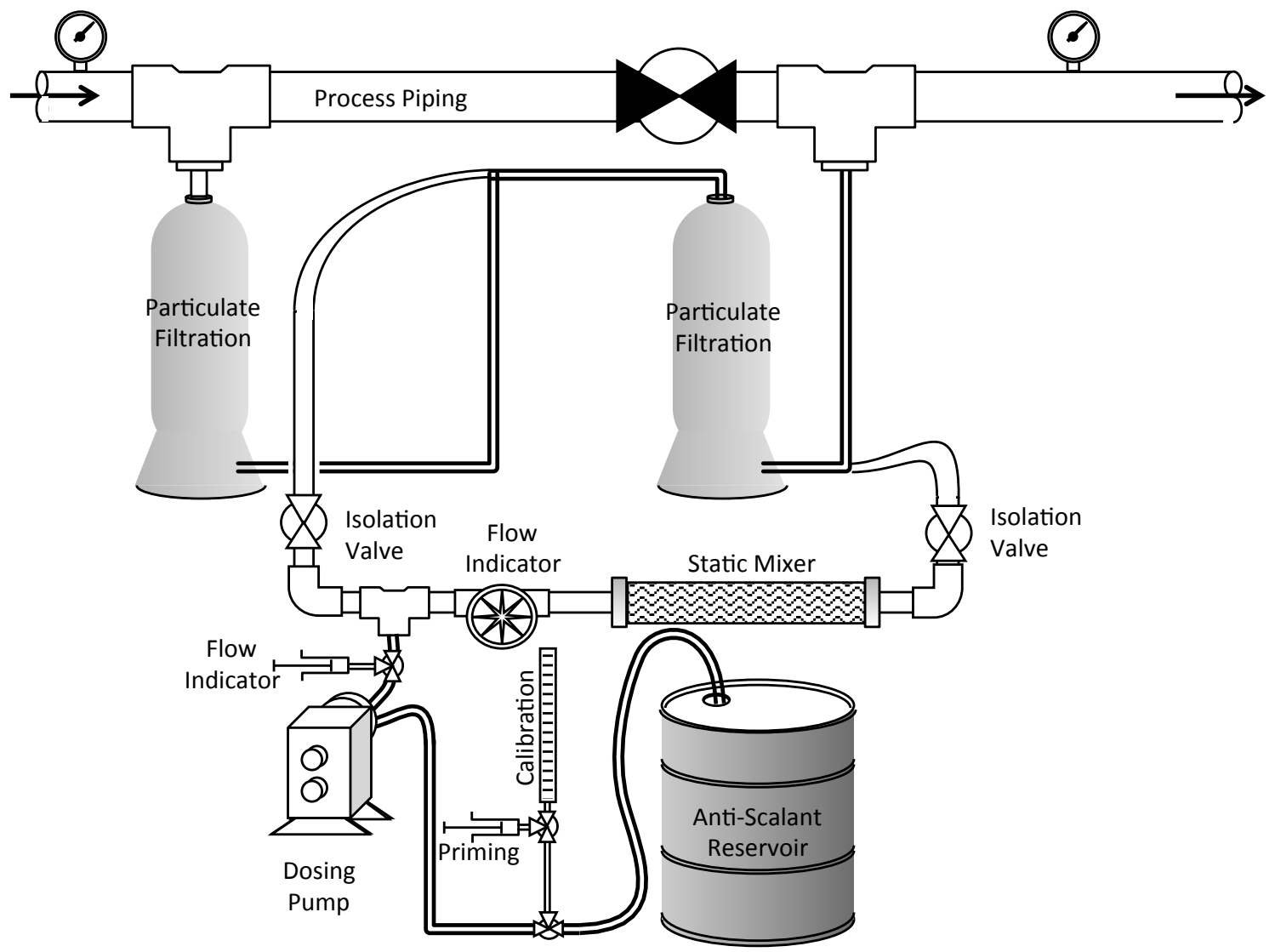

Figure 2 Antiscalant dosing system located at the point of process water particulate filtration.

\section{Test Methodology}

The predominant operating indicator of scale buildup is typically increased backpressure through pipelines and components. Increased backpressure should

3 Test of a Chemical Dispersant for the Control of Scale Formation at Treatment Facility D, P. Krauter, J. Harrar, S. Orloff, May 1998, UCRLID-130568 
occur throughout the system due to scaling, but would be most prevalent, and quickest to observe, in areas of small cross-section like the heat exchanger. The increase in water temperature exiting from the heat exchanger would also be an indicator due to the decreased heat transfer efficiency. These values should be monitored as part of the determination of antiscalent effectiveness.

Another obvious indicator of scaling is the direct measurement of scale buildup on wetted surfaces. This is often observed when pipelines and other equipment are removed from the system. However, this can be tested with minimal impact to the system through the use of coupons installed in unobtrusive locations within the flow stream. A coupon is a "small" removable piece of material, similar in chemistry, form and structure to the material that is in contact with process fluid. These are inserted within the process flow stream at key locations. After a period of time the coupon can be removed, observed, weighed and tested to determine the accumulated mass, crystal structure, chemical composition and adherence to the surface. It is especially important to have various coupon materials if there are widely varying material types within the system (cast iron, black steel, copper, PVC, stainless etc). Ideally, one coupon is used for each material type, each system condition and each scale mechanism.

Both of these testing methods, system monitoring and coupon insertion, are employed in an "un-dosed" and "dosed" condition to determine the baseline and treatment effectiveness. Each condition may require several weeks of run time to develop enough scale to determine a measurable effect.

If the system is not yet built, a scaled prototype can be used that emulates all the relevant parameters including temperature, water chemistry, externally applied pressure and velocity. Installation of a slipstream on an existing systems with similar water chemistry is also a viable approach.

In addition to the field test, analytical testing of the water would be a valuable supplement to the analysis. The major analytes of concern are total hardness, total alkalinity, calcium, and total dissolved solids. Field readings of $\mathrm{pH}$ should also be recorded. Sample locations should be before and after the heat exchanger. If desired, the concentration of Belsperse 161 can be verified in the field with a test kit that measures phosphonate.

\section{Testing apparatus}

Various types of scale coupons may be purchased from commercial vendors (Figure 3). They may also be fabricated specifically for the system. The metal finishes should match those within the system. Typically 120 grit sand blasted surface treatment is sufficient. Each sample should be stamped with an ID \#. Accurate weights of each coupon must be recorded just prior to installation. Handling of the coupons should be kept to a minimum to reduce the depositing of oils or other foreign substances onto the metal surface. 


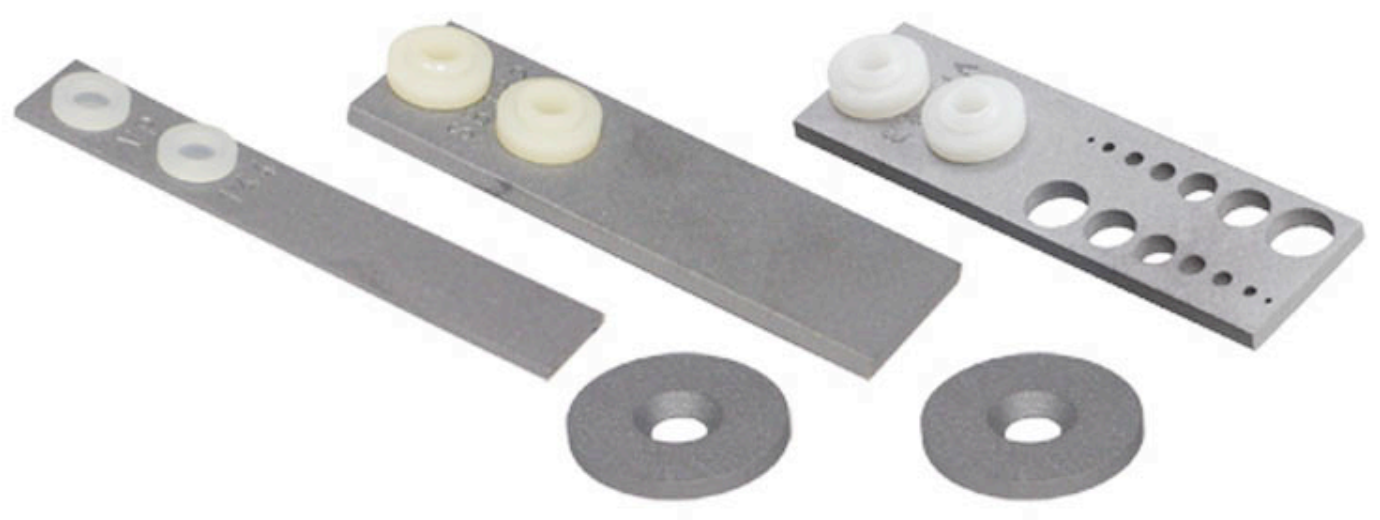

Figure 3 Coupons

The coupons can be flat plain solid metal or have multiple, various sized holes drilled through them to help quantify what size orifice is most susceptible to scale buildup at that particular velocity. The plain flat coupons are typically used to determine the scale buildup on a pipe inner surface and are installed parallel to the flow stream. The flat drilled out coupons are typically used to determine the scale buildup on boilers, heat exchangers, and manifolds and are installed perpendicular to the flow stream.

The ideal size of the coupon is dependent on the anticipated rate of scale buildup and available space. For low rates of scale buildup, a larger coupon will allow for more accumulation in total mass over a shorter time. Precision in measuring capability should be considered in this decision. The attachment of coupons to the system can be accomplished in several ways. There are commercial apparatuses that utilize a plug opening in a pipeline. Custom attachments may be fabricated to allow installation in tanks, pipes, and other equipment as appropriate.

The typical dosing pump will be a diaphragm, rotating piston, or syringe style, depending on the required dose rate. The pump should be able to supply the additive at a frequency of $\geq 1 \mathrm{~Hz}$ at a reasonable dilution (or pure if possible).

The water heater, if required, should be sized to raise the applicable flow temperature $10^{\circ} \mathrm{F}$ at $3.5 \mathrm{gpm}$. A 4 to $10 \mathrm{KW}$ industrial heater should do the trick.

The water flow meter could be any type. It's recommended that depending on the level of required oversight and automation, a transmitting unit be used to warn of system failure. 


\section{Antiscalent}

The recommended additive, Belsperse ${ }^{\circledR} 161$ is an acrylic acid polymer with sodium phosphinate (CAS No 71050-92-9). This dispersant has been developed as a highly effective scale control agent used primarily in boilers and industrial cleaning. The active ingredient of Belsperse 161 is a phosphino- carboxylic acid, or an acrylic acid polymer. It has been observed that Belsperse 161 is a good calcium carbonate and calcium sulfate dispersant. It is especially effective under high stress and high temperature conditions ${ }^{4}$.

From the MSDS (Ref. No: 71050-62-9-4, attached) for Belsperse 161 (CAS\# 71050-62-9), it states that "thermal decomposition and burning may produce carbon monoxide, carbon dioxide and phosphorous oxides". It's not classified as hazardous to health or the environment. It is stable and non-hazardous under normal conditions of use.

\section{Monitoring Setup}

Three options for approaching the setup of the scaling tests are addressed in this plan: (1) Using the designed and built system, (2) Using a similar system with a heat exchanger, and (3) Using a similar system without a heat exchanger. The three systems are diagrammed in Figure 4 through Figure 6. The assumptions and correlations between the collected data and each type of setup are listed in Table 1. Other approaches may combine characteristics of these proposed options.

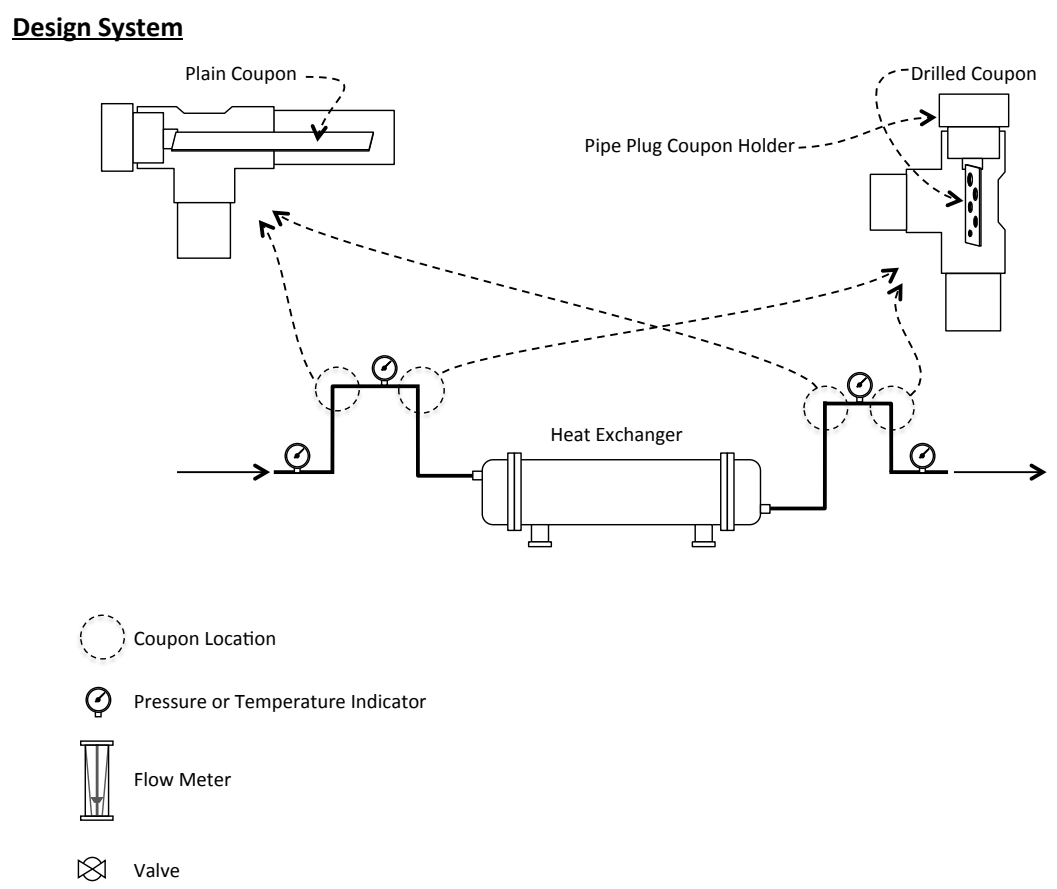

Figure 4 Design system example

4 Robert R. Cavano. "Polymers for cooling water treatment", Water Matters, Scranton Associates, Inc., Part II, Copolymers Analyst, pp 1-14, Winter 2001 


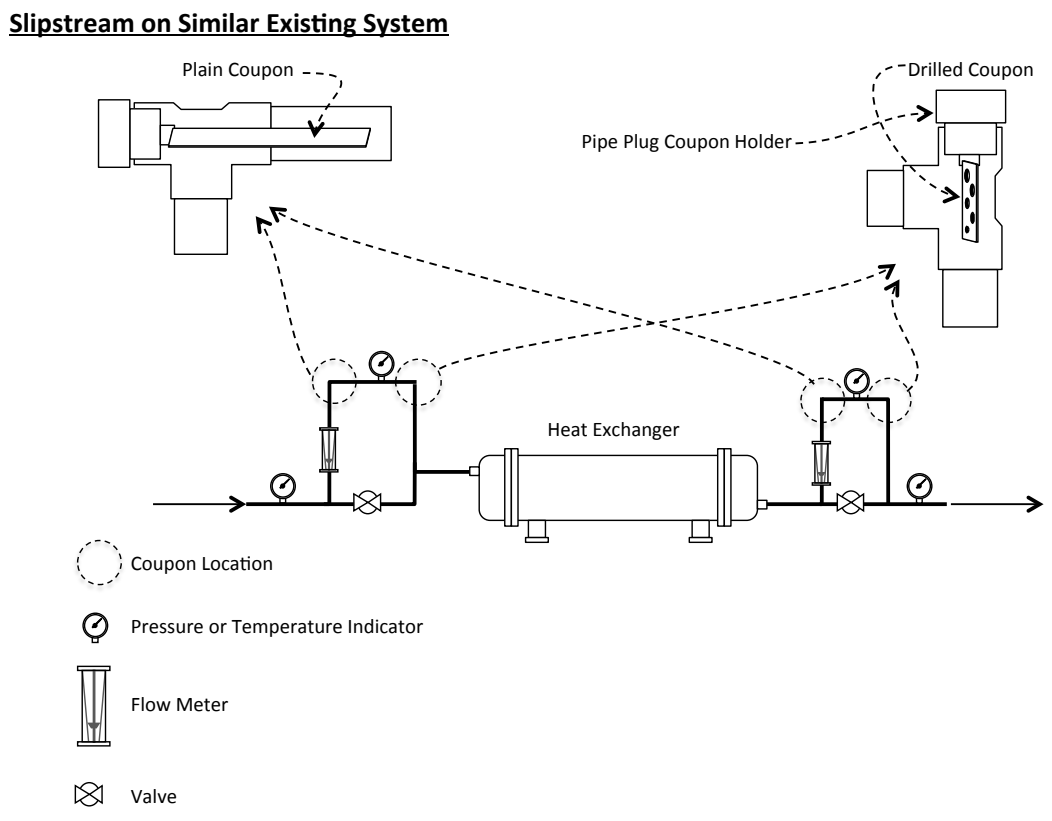

Figure 5 Slipstsream example with heat exchanger

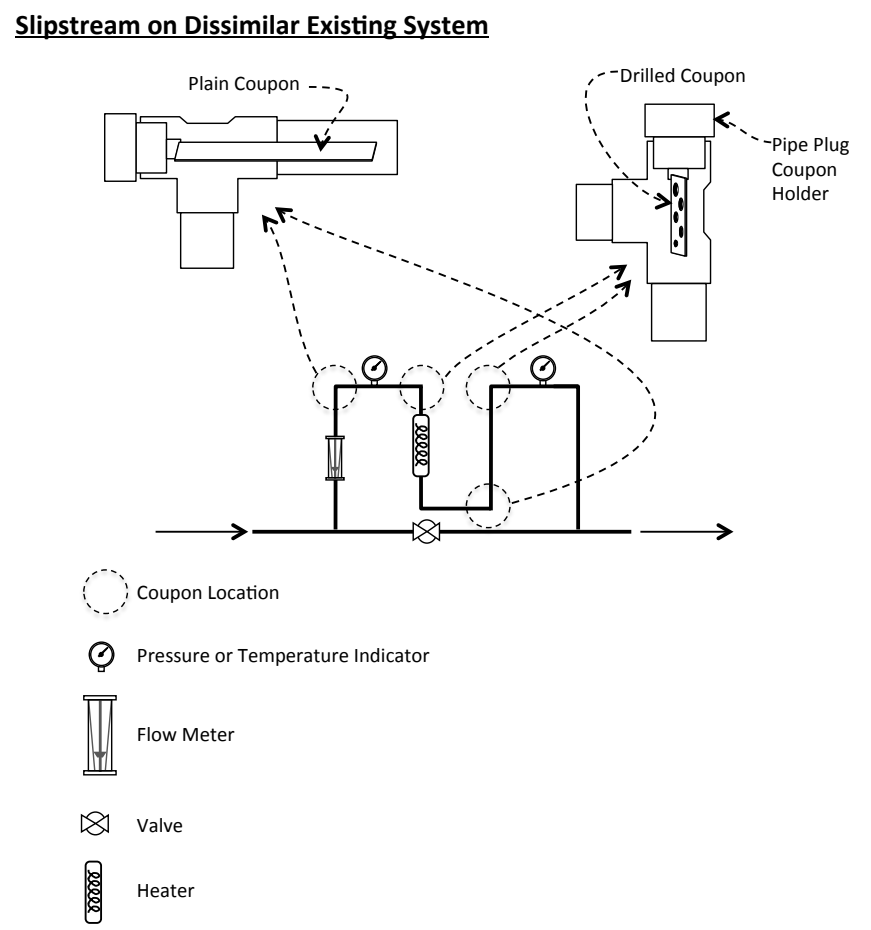

Figure 6 Slipstream example without existing heat exchanger 


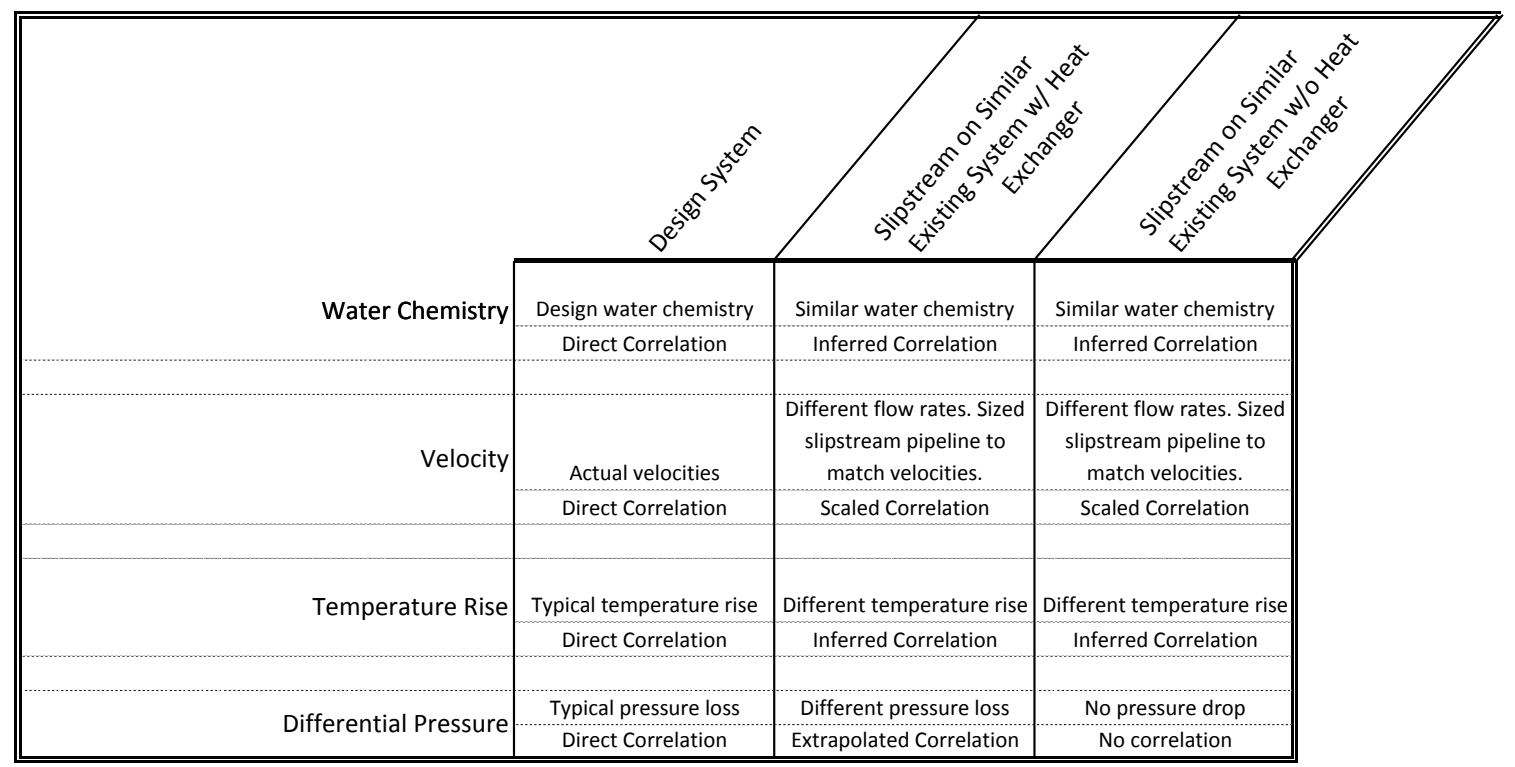

Coupons should be placed just before and after the heat source so that the effect of the elevated temperature can be assessed. The coupons should be installed into the system so that the "surface area" mimics the potential buildup surfaces. This may include both a perpendicular and parallel trajectory with the flow stream. Coupons should not be freely suspended as this could cause scale to be knocked or sheared off.

For the measurement of differential pressure and temperature rise, applicable gages should be installed in the system at locations representative of initial and final conditions.

The test parameters are listed in Table 2. The baseline and treatment monitoring and sampling schedules are included as Table 3 and Table 4. It would be advisable to also include all ion species, silica (as SiO2), organics and a typical metals suite, as part of the baseline sampling. Note that the duration of the test is not given. There is no way of knowing how long it would take to build up enough scale on the coupons to get accurate and useful data. Monitoring of temperature and pressure should give an indication of scale buildup. Intermediate samples may be taken as appropriate to verify and enable the non-linear extrapolation of scale buildup. An iterative approach may be required to adjust the schedule for "intermediate" and "end" measuring events. 
Table 2 Testing option parameters

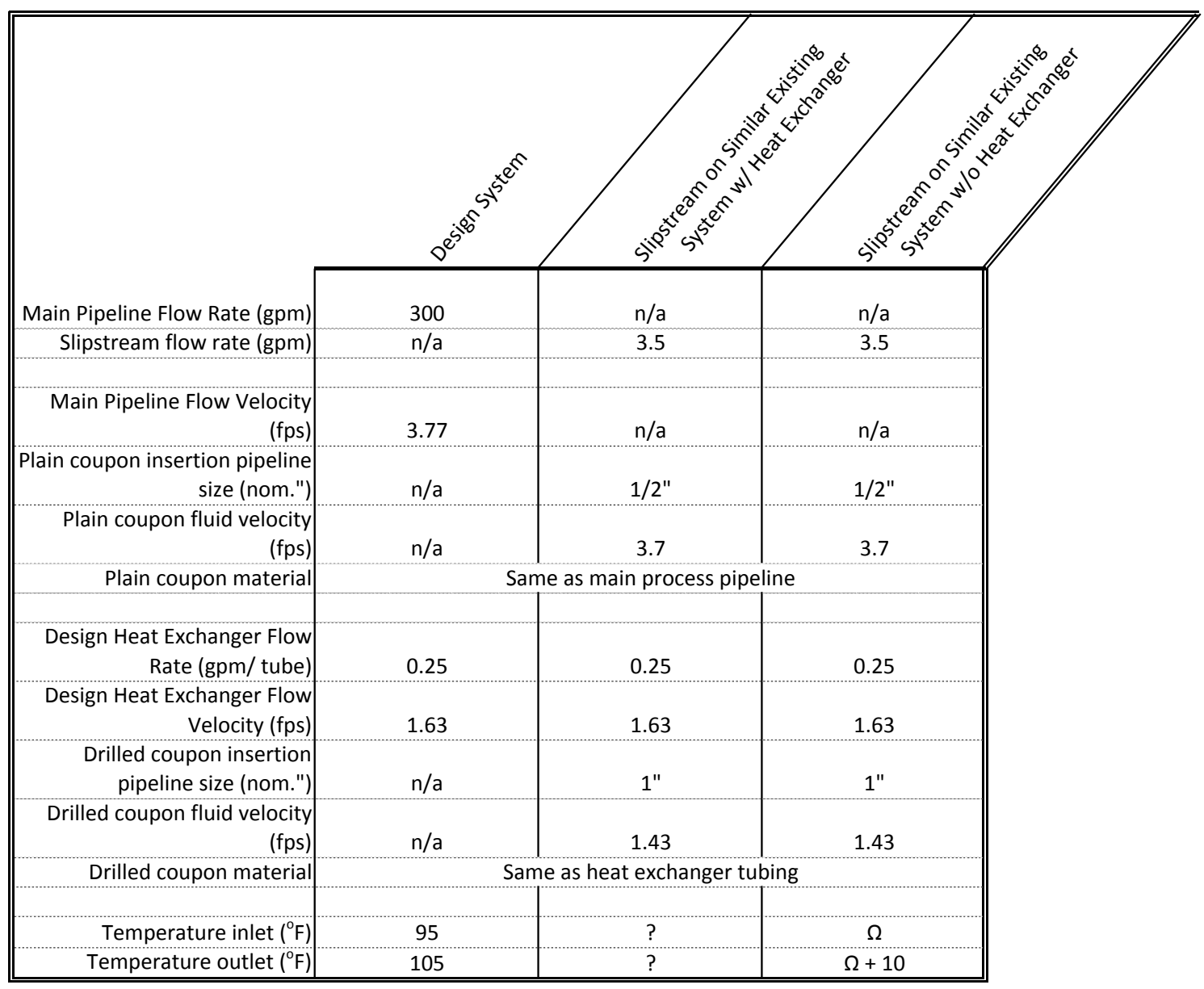


Table 3 Baseline sampling, monitoring schedule

\begin{tabular}{|c|c|c|}
\hline \multicolumn{3}{|c|}{ For setup on the designed system } \\
\hline \multirow{2}{*}{\multicolumn{3}{|c|}{$\begin{array}{l}\text { Study } \\
\text { Type }\end{array}$}} \\
\hline & & \\
\hline \multicolumn{3}{|c|}{ Where } \\
\hline & What & When/Duration \\
\hline \multicolumn{3}{|c|}{ Baseline } \\
\hline \multirow{2}{*}{\multicolumn{3}{|c|}{$\begin{array}{l}\text { Samples } \\
\text { Prior to heat source }\end{array}$}} \\
\hline & & \\
\hline & total hardness & Once \\
\hline & total alkalinity & Once \\
\hline & calcium & Once \\
\hline & total dissolved solids & Once \\
\hline \multicolumn{3}{|c|}{ After to heat source } \\
\hline & total hardness & End \\
\hline & total alkalinity & End \\
\hline & calcium & End \\
\hline & total dissolved solids & End \\
\hline \multicolumn{3}{|c|}{ Readings } \\
\hline \multicolumn{3}{|c|}{ Prior to heat source } \\
\hline & $\mathrm{pH}$ & Once \\
\hline & Temperature & Daily \\
\hline & Pressure & Daily \\
\hline & Flow rate & Daily \\
\hline \multicolumn{3}{|c|}{ After to heat source } \\
\hline & $\mathrm{pH}$ & Once \\
\hline & Temperature & Daily \\
\hline & Pressure & Daily \\
\hline \multicolumn{3}{|c|}{$\begin{array}{l}\text { Measurments } \\
\text { Prior to heat source }\end{array}$} \\
\hline \multicolumn{3}{|c|}{ Prior to heat source } \\
\hline & Plain Coupon \#, weight & Beginning/Intermediate/End \\
\hline & Drilled Coupon \#, weight & Beginning/Intermediate/End \\
\hline & Plain Coupon scale thickness & Intermediate/End \\
\hline & Drilled Coupon scale thickness & Intermediate/End \\
\hline & Drilled coupon hole scale & Intermediate/End \\
\hline \multicolumn{3}{|c|}{ After to heat source } \\
\hline & Plain Coupon \#, weight & Beginning/Intermediate/End \\
\hline & Drilled Coupon \#, weight & Beginning/Intermediate/End \\
\hline & Plain Coupon scale thickness & Intermediate/End \\
\hline & Drilled Coupon scale thickness & Intermediate/End \\
\hline & Drilled coupon hole scale & Intermediate/End \\
\hline
\end{tabular}

Table 4 Treatment Sampling and monitoring schedule

\begin{tabular}{|c|c|c|}
\hline \multicolumn{2}{|c|}{$\begin{array}{l}\text { For setup on the designed system } \\
\text { Study } \\
\text { Type }\end{array}$} & When/Duration \\
\hline \multicolumn{3}{|l|}{ Treatment } \\
\hline \multicolumn{3}{|c|}{ Samples } \\
\hline \multicolumn{3}{|c|}{$\begin{array}{l}\text { Prior to Belsperse } 161 \text { injection } \\
\text { (phosphonate) }\end{array}$} \\
\hline \multicolumn{3}{|c|}{ Prior to heat source } \\
\hline & $\begin{array}{l}\text { Belsperse } 161 \text { concentration } \\
\text { (phosphonate) }\end{array}$ & Weekly \\
\hline & After to heat source & End \\
\hline & total hardness & End \\
\hline & total alkalinity & End \\
\hline & calcium & End \\
\hline & total dissolved solids & End \\
\hline \multicolumn{3}{|c|}{ Readings } \\
\hline \multicolumn{3}{|c|}{ Prior to heat source } \\
\hline & $\mathrm{pH}$ & Once \\
\hline & Temperature & Daily \\
\hline & Pressure & Daily \\
\hline & Flow rate & Daily \\
\hline \multicolumn{3}{|c|}{ After to heat source } \\
\hline & $\mathrm{pH}$ & Once \\
\hline & Temperature & Daily \\
\hline & Pressure & Daily \\
\hline \multicolumn{3}{|c|}{ Measurments } \\
\hline \multicolumn{3}{|c|}{ Prior to heat source } \\
\hline & Plain Coupon \#, weight & Beginning/Intermediate/End \\
\hline & Drilled Coupon \#, weight & Beginning/Intermediate/End \\
\hline & Plain Coupon scale thickness & Intermediate/End \\
\hline & Drilled Coupon scale thickness & Intermediate/End \\
\hline & Drilled coupon hole scale & Intermediate/End \\
\hline \multicolumn{3}{|c|}{ After to heat source } \\
\hline & Plain Coupon \#, weight & Beginning/Intermediate/End \\
\hline & Drilled Coupon \#, weight & Beginning/Intermediate/End \\
\hline & Plain Coupon scale thickness & Intermediate/End \\
\hline & Drilled Coupon scale thickness & Intermediate/End \\
\hline & Drilled coupon hole scale & Intermediate/End \\
\hline
\end{tabular}


The location of the injection of antiscalant would typically occur upstream of a long pipeline that would assist with mixing. For the setup on "similar systems", with or without a heat exchanger, the injection system may either be installed on the main process line or as part of the slipstream. Be advised that the slipstream flows are low and the injection rates into low flow are also very low, sometimes too low for many types of dosing pumps. It was calculated that to maintain a concentration of Belsperse in a $3.5 \mathrm{gpm}$ flow at $0.63 \mathrm{ppm}$ using an initial dilution of $20 \%$ would require an injection rate of $0.040 \mathrm{ml} / \mathrm{min}$. It's advisable that the pulse frequency of any dosing pump be maintained at $\geq 1 \mathrm{~Hz}$ to maximize the even distribution of additive throughout the linear dimension of water flow. Greater injection flow rates may be specified if the Belsperse is further diluted, but keep in mind, the greater dilution, the greater required reservoir capacity. Ideally, it's best to inject the additive in its pure concentration to minimize handling costs. An automated dilution system could be designed, but it's not likely that the final design will require it given the high (300-600 gpm) process flow rates.

Once it's been determined what the injection method, dilution and process flow rate will be, the dosing pump can be specified based in Figure 7 which is particular to the water chemistry of the design system. These values may change (because the required dose concentration will change) if the water chemistry, based on sampling, is significantly different than the original assumptions.

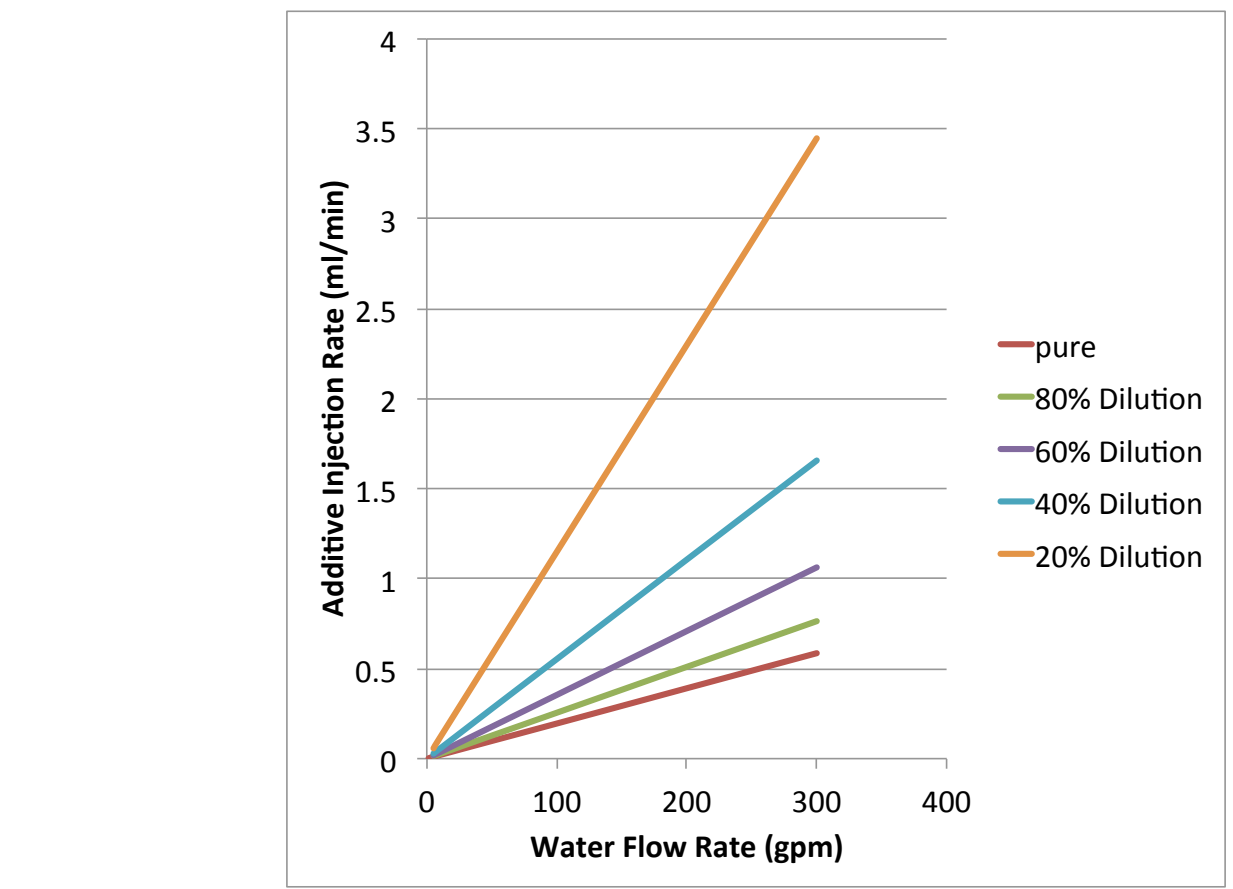

Figure 7 Dosing rates for various process flows and antiscalant dilutions 


\title{
Analysis
}

The analysis of the data accumulated during testing should allow the estimation of an expected time to unacceptable scale buildup. No antiscalant will keep a system scale free forever. A system periodically requires either replacement or de-scaling using an acid wash or some similar technique. Analysis of the various parameters and indicators should be scheduled throughout the test to identify trends, gage testing duration, and problematic developments. It is anticipated that an inorganic chemist would analyze the water chemistry to verify scaling pre-cursers and system effects on water characteristics.

\section{Suggested Equipment/Materials Manufactures and Suppliers}

\author{
Dosing pump \\ LMI Milton Roy (diaphragm pump) \\ Fluid Metering Incorporated (rotating piston pump) \\ KD Scientific (syringe pump) \\ Water Heaters \\ Infinity Fluids (industrial inline water heaters) \\ Flow Meters \\ King Instrument Company (Rotameter with alarm option) \\ Coupons \\ Metal Samples Corrosion Monitoring Systems \\ Caproco
}

Belsperse 161 Antiscalant

FMC Corporation

BWA Water Additives

Houghton Chemical Corporation

Belsperse (phosphonate) test kit

LaMotte Phosphonate tester model: 4068 